\title{
The Mutualistic Fungus Piriformospora indica Protects Barley Roots from a Loss of Antioxidant Capacity Caused by the Necrotrophic Pathogen Fusarium culmorum
}

\author{
Borbála D. Harrach, ${ }^{1}$ Helmut Baltruschat, ${ }^{2}$ Balázs Barna, ${ }^{1}$ József Fodor, ${ }^{1}$ and Karl-Heinz Kogel ${ }^{3}$ \\ ${ }^{1}$ Plant Protection Institute, Centre for Agricultural Research, Hungarian Academy of Sciences, Herman Ottó út 15, H-1022, \\ Budapest, Hungary; ${ }^{2}$ Anhalt University of Applied Sciences, Center of Life Sciences, Institute of Bioanalytical Sciences, \\ Strenzfelder Allee 28, D-06406 Bernburg, Germany; ${ }^{3}$ Research Center for Bio Systems, Land Use, and Nutrition, Justus \\ Liebig University Giessen, Heinrich-Buff-Ring 26-32, D-35392 Giessen, Germany
}

Submitted 10 September 2012. Accepted 5 February 2013.

\begin{abstract}
Fusarium culmorum causes root rot in barley (Hordeum vulgare), resulting in severely reduced plant growth and yield. Pretreatment of roots with chlamydospores of the mutualistic root-colonizing basidiomycete Piriformospora indica (subdivision Agaricomycotina) prevented necrotization of root tissues and plant growth retardation commonly associated with Fusarium root rot. Quantification of $\mathrm{Fu}$ sarium infections with a real-time polymerase chain reaction assay revealed a correlation between root rot symptoms and the relative amount of fungal DNA. Fusarium-infected roots showed reduced levels of ascorbate and glutathione (GSH), along with reduced activities of antioxidant enzymes such as superoxide dismutase, ascorbate peroxidase, GSH reductase, dehydroascorbate reductase, and monodehydroascorbate reductase. Consistent with this, Fusariuminfected roots showed elevated levels of lipid hydroperoxides and decreased ratios of reduced to oxidized forms of ascorbate and GSH. In clear contrast, roots treated with $P$. indica prior to inoculation with $F$. culmorum showed levels of ascorbate and GSH that were similar to controls. Likewise, lipid peroxidation and the overall reduction in antioxidant enzyme activities were largely attenuated by $P$. indica in roots challenged by $F$. culmorum. These results suggest that $P$. indica protects roots from necrotrophic pathogens, at least partly, through activating the plant's antioxidant capacity.
\end{abstract}

Piriformospora indica is a root-colonizing basidiomycete fungus that increases plant growth of a wide range of crop species (Peškan-Berghöfer et al. 2004; Qiang et al. 2012; Weiss et al. 2011). The fungus is known to reproduce asexually by generating thick-walled chlamydospores, and in clear contrast to arbuscular mycorrhiza, can be cultured on synthetic media (Varma et al. 1999; Verma et al. 1998). Plants colonized with $P$. indica exhibit enhanced tolerance against abiotic stress and resistance to microbial pathogens. Several studies have demonstrated that $P$. indica confers salt and drought tolerance to host plants, but the underlying mechanism is not fully elucidated (Baltruschat et al. 2008; Cruz et al. 2010; Franken 2012; Sherameti et al. 2008; Sun et al. 2010; Waller et al. 2005; Zarea et al. 2012).

Corresponding author: József Fodor; E-mail: fodor.jozsef@agrar.mta.hu

(C) 2013 The American Phytopathological Society
An important feature of plant responses to environmental stresses is that the balance between production and scavenging of reactive oxygen species (ROS) is shifted towards higher ROS levels (Apel and Hirt 2004). Excess ROS subsequently induce lipid peroxidation of cell membranes and damage to proteins and nucleic acids. Growing evidence suggests that endophytic fungi enhance tolerance of host plants to abiotic stress by altering their antioxidant activity (Hamilton and Bauerle 2012; Rodriguez et al. 2008). Consistent with this, colonization by $P$. indica prevents salt- and drought-induced lipid peroxidation in barley and Chinese cabbage roots, respectively (Baltruschat et al. 2008; Sun et al. 2010). This beneficial effect is associated with significant changes in plant redox metabolism and accumulation of high levels of ascorbate due to increased activities in key antioxidant enzymes, such as dehydroascorbate reductase (DHAR, EC 1.8.5.1) and monodehydroascorbate reductase (MDHAR, EC 1.6.5.4) (Baltruschat et al. 2008; Waller et al. 2005). Moreover, upregulation of DHAR and MDHAR in Arabidopsis thaliana is essential for a mutualistic association with $P$. indica (Vadassery et al. 2009). In addition to its role in abiotic stress tolerance, $P$. indica confers resistance to a range of microbial pathogens in various crop plants, including barley, lentil, maize, tomato, and wheat (Deshmukh and Kogel 2007; Dolatabadi et al. 2012; Fakhro et al. 2010; Kumar et al. 2009; Serfling et al. 2007; Waller et al. 2005). Most of these studies have been focused on soil-borne diseases such as Fusarium root rot of cereals. It is well-established that F. culmorum utilizes production of ROS to accelerate cell death and facilitate subsequent infection (Cuzick et al. 2009). Accordingly, an increase in oxidative stress was observed in barley and wheat seedlings affected by Fusarium head blight and root rot (Boddu et al. 2006; Desmond et al. 2008; Khoshgoftarmanesh et al. 2010).

We show here that $P$. indica counteracts root infections by the necrotrophic pathogen $F$. culmorum and that this beneficial effect is associated with altered antioxidant activity of root cells suited to detoxify pathogen-induced excess ROS.

\section{RESULTS}

Quantification of $F$. culmorum in barley roots.

Consistent with earlier studies, three-week-old $P$. indicacolonized barley showed enhanced shoot and root biomass (Fig. 1) (Deshmukh and Kogel 2007; Waller et al. 2005). In contrast, shoot and root biomass was strongly reduced by Fusarium culmorum infection within two weeks of inoculation. 
However, when $P$. indica-colonized plants were challengeinoculated with $F$. culmorum, neither severe root rot symptoms nor growth retardation was observed (Fig. 1).

The ratio of $F$. culmorum DNA to plant DNA was calculated to monitor fungal root infection, by quantitative real-time polymerase chain reaction (qPCR) using primers specific for the fungal Tri12 gene of the trichothecene pathway and for the translation elongation factorl $\alpha(E F 1 \alpha)$ gene from barley. The qPCR analysis confirmed that roots were extensively colonized with $F$. culmorum two weeks after inoculation (Fig. 2). In contrast, preinoculation with $P$. indica resulted in reduced colonization of roots by $F$. culmorum, which is consistent with less root rot-symptom expression and a reduced loss of biomass. No amplification product of the F. culmorum-specific Tril2 gene was observed when template DNA was extracted either from uninoculated or $P$. indica-colonized roots.

\section{$P$. indica protects Fusarium-infected roots}

from a loss of ascorbate and glutathione (GSH).

We assessed the antioxidant status of barley roots that were colonized either by $P$. indica, $F$. culmorum, or a combination of these fungi. Colonization by $P$. indica resulted in a 2.5 -fold increase in ascorbate level and a $70 \%$ increase in the ratio of reduced to oxidized ascorbate (dehydroascorbate, DHA) in 3week-old plants compared with the controls (Fig. 3). In contrast, inoculation of roots with $F$. culmorum caused a $70 \%$ reduction in root ascorbate after two weeks, although it did not result in a significant accumulation of DHA. Accordingly, the ratio of ascorbate to DHA decreased by about $70 \%$ in $\mathrm{Fu}$ sarium-infected roots. However, when roots were inoculated with $P$. indica one week prior to $F$. culmorum, root ascorbate and DHA levels were similar to that in control plants (Fig. 3).

To extend this analysis, we measured the concentration of reduced GSH in infected and uninfected barley roots. Three weeks after inoculation with $P$. indica, the level of GSH was

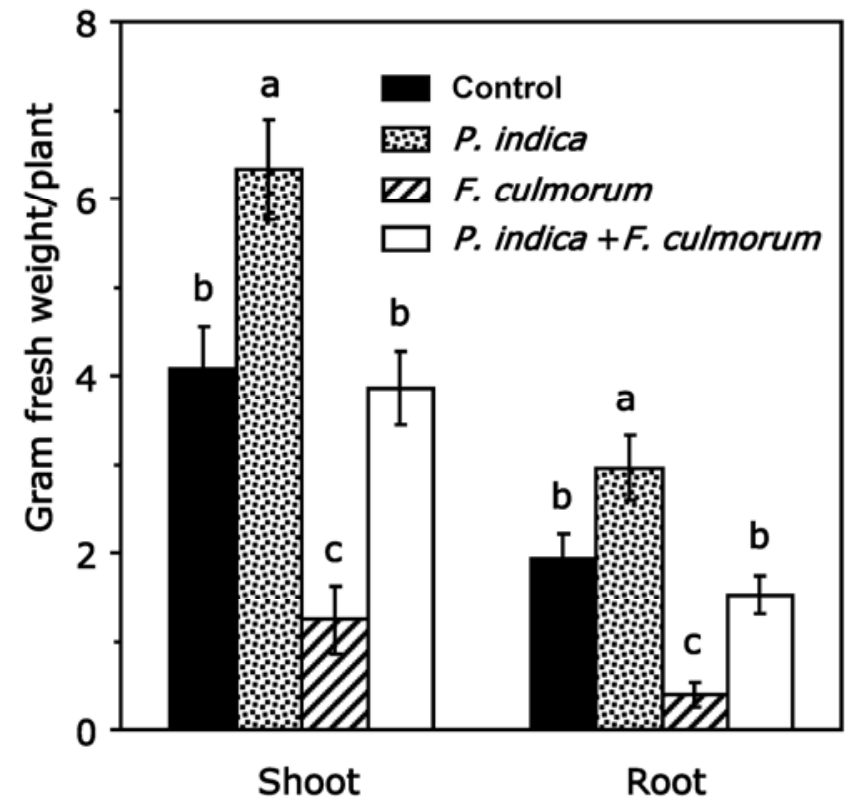

Fig. 1. Shoot and root fresh weight of three-week-old barley plants preinoculated with Piriformospora indica and challenged with Fusarium culmorum. Two-day-old seedlings were dip-inoculated with $5 \times 10^{5} \mathrm{P}$. indica chlamydospores per milliliter or water (mock) before sowing. One-week-old seedlings were transferred to pots containing or not containing inoculum of $F$. culmorum. Control seedlings were mock-inoculated twice at two days and one week. Data are means \pm standard deviation ( $n=4$ plants). The experiment was repeated twice with similar results. Different letters indicate significant differences in shoot and root biomass ( $P \leq 0.05$, Tukey test). slightly, but not significantly, higher in colonized roots as compared with the uncolonized controls (Fig. 4). In contrast, F. culmorum infection resulted in about a $40 \%$ reduction in the GSH level two weeks after inoculation (Fig. 4). Unlike DHA, the content of oxidized GSH (GSSG) increased significantly (about 2.6-fold) in response to F. culmorum infection. Accordingly, the ratio of reduced GSH to GSSG decreased substantially (about fourfold; Fig. 4). As in the case of ascorbate and DHA, depletion of the GSH content and the ratio of GSH to GSSG were prevented by preinoculation with $P$. indica.

\section{Ascorbate-GSH cycle enzymes.}

We addressed the question of whether activities of antioxidant enzymes were changed in infected roots and, thus, may contribute to infection-related changes in the redox state of ascorbate and GSH. Elevated cellular ascorbate and GSH levels suggest that enzymes involved in the regeneration of the two antioxidants show increased activities. Consistent with this, $P$. indica-colonized barley roots exhibited an approximately 35\% increase in both DHAR and MDHAR activities (Table 1), while ascorbate peroxidase (APX, EC 1.11.1.11) and GSH reductase (GR, EC 1.6.4.2) were only slightly (insignificantly) enhanced. On the contrary, inoculation of plants with $F$. culmorum resulted in a marked reduction in the activities of all the enzymes of the ascorbate-GSH cycle (APX, 60\%; GR, 28\%; DHAR, 44\%; MDHAR, 60\%) as compared with controls (Table 1). This reduction of antioxidative enzymes was abolished in $P$. indica-colonized plants in which activities of APX, GR, DHAR, and MDHAR were 3.9-fold, twofold, 1.4-fold, and 1.9-fold higher, respectively, compared with roots infected only with $F$. culmorum (Table 1 ). When com-

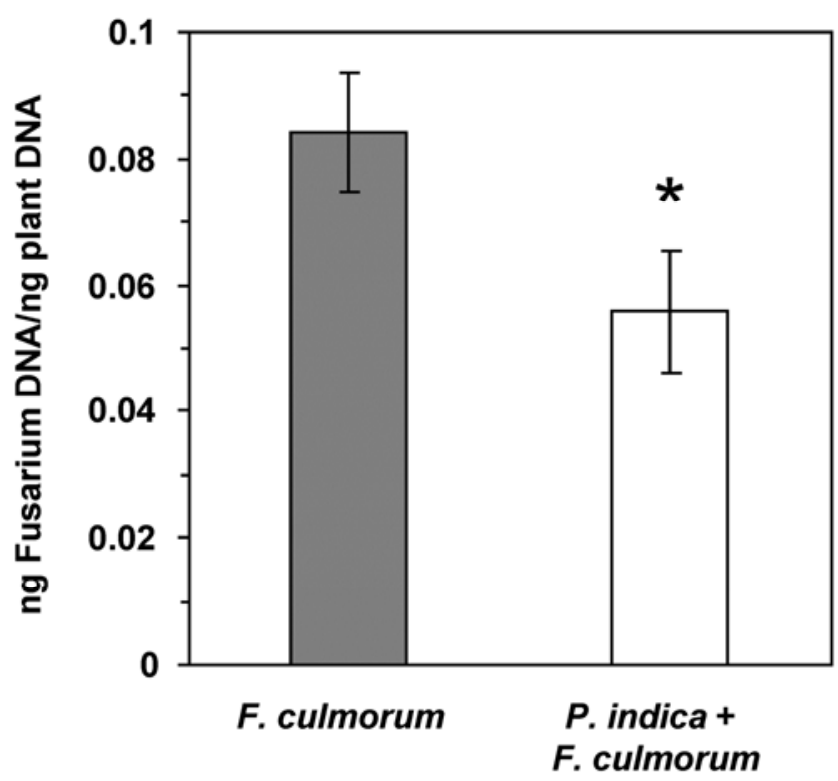

Fig. 2. Concentrations of Fusarium culmorum DNA in roots of threeweek-old barley plants preinoculated with Piriformospora indica and challenged with $F$. culmorum. Two-day-old seedlings were dip-inoculated with $5 \times 10^{5}$ chlamydospores per milliliter of $P$. indica or water (mock) before sowing. One-week-old seedlings were transferred to pots containing or not containing inoculum of $F$. culmorum. Control seedlings were mock-inoculated twice at two days and one week. Fusarium DNA levels were measured by real-time polymerase chain reaction and were normalized using the plant EF1 $\alpha$ assay (Nielsen et al. 2012). Relative biomass of the fungus (means \pm standard deviation) is expressed as the ratio of fungal DNA relative to plant DNA. No amplification product of the F. culmorum-specific Tri12 gene was observed when template DNA was prepared from plants not inoculated with $F$. culmorum. Data are based on three independent experiments run in triplicate. Student's $t$-test indicated significant difference in F. culmorum colonization $(* P<0.05)$. 
pared with controls, dually inoculated roots showed 60 and $40 \%$ greater APX and GR activities, respectively, while DHAR activity was not significantly different and MDHAR activity was $25 \%$ less. Together, these data demonstrate that the mutualistic, root-colonizing fungus $P$. indica abolishes detrimental effects on the host plant's antioxidant system caused by the necrotrophic pathogen $F$. culmorum.

\section{$P$. indica protects Fusarium-infected roots}

from loss of superoxide dismutase (SOD) activities.

Compared with control plants, total activity of SOD (EC 1.15.1.1) was increased by $62 \%$ in $P$. indica-colonized threeweek-old plants, whereas it was reduced by $56 \%$ in roots inoculated with $F$. culmorum. Yet, when $P$. indica-colonized seedlings were challenged with $F$. culmorum, the pathogen-induced reduction in SOD activity was completely abolished (Table 1).

Similarly, activity of catalase (CAT, EC 1.11.1.6) increased significantly in response to $P$. indica (Table 1). We found that $P$. indica elevated the CAT activity by $46 \%$ in roots as compared with uncolonized control plants. However, unlike SOD, CAT activity did not change significantly upon inoculation with F. culmorum (Table 1).

\section{$P$. indica protects $F$ usarium-infected roots from extensive lipid peroxidation.}

Next, we assessed levels of lipid peroxides (LOOH) in roots of three-week-old plants using the ferrous oxidation xylenol orange (FOX) assay (Do et al. 1996). Roots colonized with $P$. indica as well as roots of control plants contained low amounts of LOOH (approximately $70 \mathrm{nmol}$ per gram of fresh weight [FW]; Fig. 5). In contrast, fivefold higher levels of LOOH

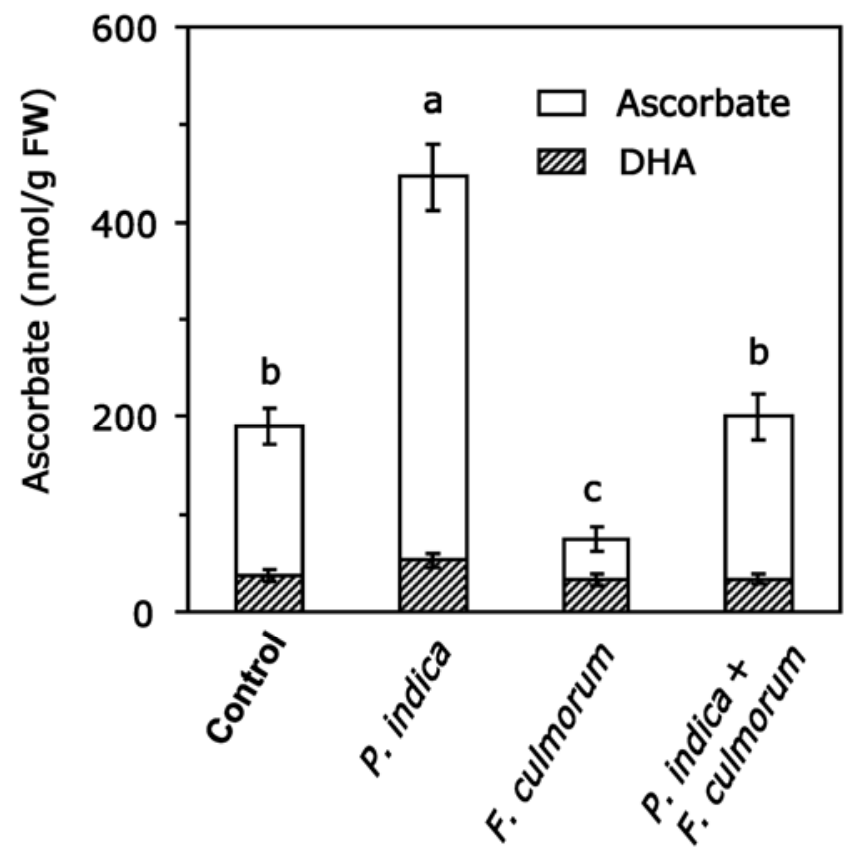

Fig. 3. Levels of reduced ascorbate (white bars) and dehydroascorbate (DHA, hatched bars) in roots of three-week-old barley plants preinoculated with Piriformospora indica and challenged with Fusarium culmorum. Two-day-old seedlings were dip-inoculated with $5 \times 10^{5}$ chlamydospores per milliliter of $P$. indica or water (mock) before sowing. One-week-old seedlings were transferred to pots containing or not containing inoculum of $F$. culmorum. Control seedlings were mock-inoculated twice at two days and one week. Data are means \pm standard deviation $(n=$ 4 plants). The experiment was repeated twice with similar results. Different letters indicate significant differences in reduced ascorbate at $P \leq 0.05$ (Tukey test). Levels of DHA did not change significantly at $P \leq 0.05$. FW $=$ fresh weight. were found after inoculation with $F$. culmorum. Notably, pretreatement with $P$. indica at least partially protected roots against lipid peroxidation induced by infection with $F$. culmorum (approximately 160 vs. $330 \mathrm{nmol} \mathrm{LOOH}$ per gram of FW; Fig. 5).

\section{DISCUSSION}

Abiotic environmental stress and infections by microbial pathogens cause oxidative stress in plants via enhanced generation of ROS (Apel and Hirt 2004). High levels of ROS trigger cellular injury and cell death. To avoid this damage, plants have evolved enzymatic and nonenzymatic antioxidant mechanisms acting in concert to detoxify ROS (Foyer and Noctor 2005). Ascorbate is the major low-molecular weight antioxidant compound playing a central role in the cellular defense against oxidative damage (Conklin et al. 1996; Eltayeb et al. 2007; Zhang et al. 2011). $P$. indica-induced abiotic stress tolerance was shown to be associated with elevated levels of ascorbate and a high ascorbate/DHA ratio, along with increased DHAR and MDHAR enzyme activities in plant roots (Baltruschat et al. 2008; Vadassery et al. 2009; Waller et al. 2005). Moreover, systemic resistance mediated by the root-colonizing endophyte against powdery mildew disease is associated with an increased level of leaf GSH and GR enzyme activity (Waller et al. 2005).

In the present study, we analyzed the size and redox state of total ascorbate and GSH pools in barley roots inoculated with $P$. indica and the necrotrophic fungus $F$. culmorum. The observed decrease in the level of reduced forms of ascorbate and GSH along with the decrease in the ratios of reduced to oxidized forms in F. culmorum infected roots (single infection) suggests that the necrotrophic fungus causes detrimental oxid-

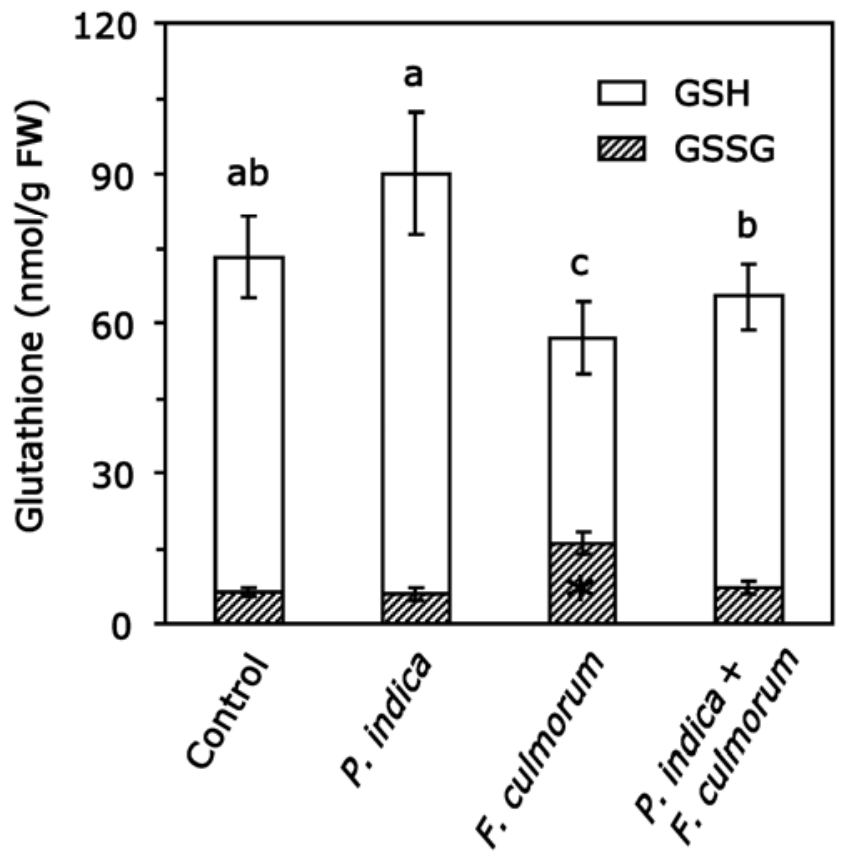

Fig. 4. Levels of reduced glutathione (GSH, white bars) and glutathione disulfide (GSSG, hatched bars) in roots of three-week-old barley plants preinoculated with Piriformospora indica and challenged with Fusarium culmorum. Two-day-old seedlings were dip-inoculated with $5 \times 10^{5}$ chlamydospores per milliliter of $P$. indica or water (mock) before sowing. One-week-old seedlings were transferred to pots containing or not containing inoculum of $F$. culmorum. Control seedlings were mock-inoculated twice at two days and one week. Data are means \pm standard deviation $(n=$ 4 plants). The experiment was repeated twice with similar results. Different letters indicate significant differences in GSH at $P \leq 0.05$ (Tukey test). GSSG level marked with an asterisk is significantly different from that observed in mock-inoculated plants $(P \leq 0.05)$. $\mathrm{FW}=$ fresh weight. 
ative stress. Our data show that $P$. indica could abolish the adverse effect of Fusarium infection on ascorbate and GSH in barley roots, as it has previously been demonstrated for salinityinduced stress.

Lipid peroxidation in living organisms subjected to oxidative stress has been widely accepted as an indication of early damage by ROS (Halliwell and Chirico 1993). We observed a fivefold increase in peroxide content of Fusarium-infected barley roots. This observation is consistent with previous studies that detected oxidative stress during infection of wheat roots by various $\mathrm{Fu}$ sarium species (Desmond et al. 2008; Khoshgoftarmanesh et al. 2010). We found that $P$. indica robustly attenuated the $F$. culmorum-induced accumulation of peroxides.

The present study also confirms that the shift in the redox status to a more oxidizing cellular environment (decreased ascorbate/DHA and GSH/GSSG ratios) in Fusarium-infected barley roots is accompanied by a significant reduction in the activities of antioxidative enzymes SOD, APX, GR, DHAR, and MDHAR. Significantly, preinoculation of roots with $P$. indica almost completely abolishes the Fusarium-induced decrease in antioxidant capacity. Conflicting results were reported

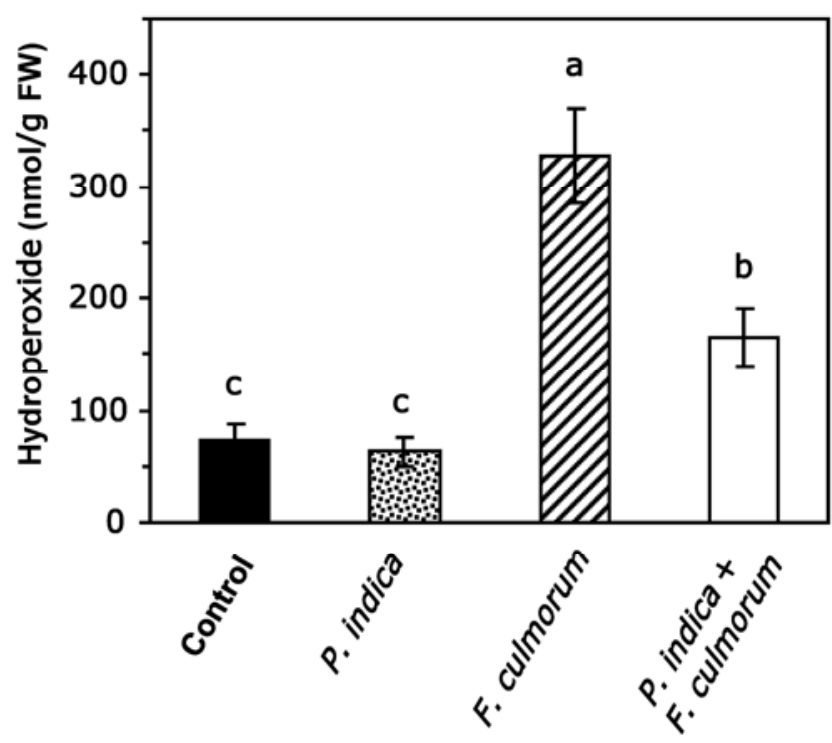

Fig. 5. Peroxide levels in roots of three-week-old barley plants preinoculated with Piriformospora indica and challenged with Fusarium culmorum. Two-day-old seedlings were dip-inoculated with $5 \times 10^{5}$ chlamydospores per milliliter of $P$. indica or water (mock) before sowing. One-week-old seedlings were transferred to pots containing or not containing inoculum of F culmorum. Control seedlings were mock-inoculated twice at two days and one week. Lipid peroxidation was measured by the ferrous $x y-$ lenol orange assay (Do et al. 1996). Hydrogen peroxide was used to construct a standard curve. Data are based on three independent experiments run in triplicate. Different letters indicate significant differences in peroxide levels at $P \leq 0.05$ (Tukey test). FW = fresh weight. by Kumar and associates (2009), who found that activities of SOD, CAT, GR, and GST increased markedly in maize roots upon inoculation with $F$. verticillioides, while $P$. indica attenuated the pathogen-induced increase in CAT, GR, and GST activities. The reason for this discrepancy is not yet clear but may be explained by differences in the severity of disease symptoms and in the modulation of the plant's antioxidant system by various mycotoxins with different modes of action produced by $F$. culmorum and $F$. verticillioides in roots of barley and maize, respectively. Maize roots colonized with $F$. verticillioides showed dramatic increases (3.2- to 43-fold over uninoculated control) in enzyme activities depending on the particular antioxidant enzyme (Kumar et al. 2009). This is in sharp contrast to our results, in which $F$. culmorum infection of barley roots resulted in a decrease in SOD, APX, GR, DHAR, and MDHAR activities. We observed the same tendency in tomato roots, in which a decrease in antioxidant capacity in response to Fusarium oxysporum f. sp. lycopersici was prevented by preinoculation with $P$. indica (unpublished results). In line with our findings, Li and associates (2010) reported that SOD activity and ascorbate content decreased in roots of strawberry plants after inoculation with $F$. oxysporum f. sp. fragariae, while preinoculation with the arbuscular mycorrhiza fungus (AMF) Glomus mosseae prevented the decline in antioxidants. Similar results were obtained with SOD and ascorbate extracted from stem bases when strawberry plants were inoculated with Colletotrichum gloeosporioides causing anthracnose as well as crown and root rot ( $\mathrm{Li}$ et al. 2010). Furthermore, level of reduced ascorbate and activities of GR, APX, and DHAR decreased in roots of St. John's wort (Hypericum perforatum) after inoculation with $C$. gloeosporioides (Richter et al. 2011). In accordance with our finding, the detrimental effect of $C$. gloeosporioides on the antioxidative defense systems in $H$. perforatum roots was completely abolished by AMF (Richter et al. 2011). Taken together, these data suggest that necrotrophic fungi inhibit the antioxidant activity in attacked plant tissues and that root-colonizing mutualistic fungi protect roots from necrotrophic microbes through activation and protection of the plants' antioxidant system.

$P$. indica does not inhibit the mycelial growth of $F$. culmorum in vitro (Waller et al. 2005), but its effect on the growth of $F$. culmorum in roots had not been quantified. qPCR of the relative abundance of F. culmorum and barley DNA was performed in root tissues using specific fungal and plant genomic DNA primers (Nielsen et al. 2012). Reduced relative amounts of $F$. culmorum DNA indicated a significantly lower level of $\mathrm{Fu}$ sarium infection in dually inoculated barley roots as compared with roots with single $F$. culmorum infections. Similar findings were reported for wheat roots inoculated with $P$. indica and $F$. graminearum (Deshmukh et al. 2007), suggesting that $P$. indica does not exert a direct antifungal activity but induces resistance against Fusarium infections. However, caution is required in interpreting the qPCR data, because the ratio of $F$.

Table 1. Activities of superoxide dismutase (SOD), catalase (CAT), ascorbate peroxidase (APX), glutathione reductase (GR), dehydroascorbate reductase (DHAR), and monodehydroascorbate reductase (MDHAR) in roots of three-week-old barley plants preinoculated with Piriformospora indica and challenged with Fusarium culmorum $^{z}$

\begin{tabular}{|c|c|c|c|c|c|c|}
\hline Treatment & $\begin{array}{c}\text { SOD } \\
(\mathbf{E U / g ~ F W )}\end{array}$ & $\begin{array}{c}\text { CAT } \\
(\mu \mathrm{mol} / \mathrm{g} \text { FW } \mathrm{min})\end{array}$ & $\begin{array}{c}\text { APX } \\
(\mu \mathrm{mol} / \mathrm{g} \text { FW min })\end{array}$ & $\begin{array}{c}\text { GR } \\
(\mathrm{nmol} / \mathrm{g} \mathrm{FW} \text { min })\end{array}$ & $\begin{array}{c}\text { DHAR } \\
(\mathrm{nmol} / \mathrm{g} \text { FW } \mathrm{min})\end{array}$ & $\begin{array}{c}\text { MDHAR } \\
(\mathrm{nmol} / \mathrm{g} \mathrm{FW} \text { min) }\end{array}$ \\
\hline Control & $576 \pm 77 b$ & $70 \pm 8 c$ & $4.35 \pm 0.56 b$ & $220 \pm 23 b$ & $291 \pm 38 b$ & $334 \pm 33 b$ \\
\hline$P$. indica & $933 \pm 115 a$ & $102 \pm 12 \mathrm{ab}$ & $4.93 \pm 0.49 b$ & $266 \pm 35 \mathrm{ab}$ & $396 \pm 35 a$ & $445 \pm 29 a$ \\
\hline F. culmorum & $256 \pm 41 c$ & $86 \pm 10 b c$ & $1.75 \pm 0.31 \mathrm{c}$ & $159 \pm 25 c$ & $164 \pm 19 c$ & $133 \pm 19 d$ \\
\hline$P$. indica $+F$. culmorum & $836 \pm 99 a$ & $118 \pm 9 a$ & $6.87 \pm 0.96 a$ & $311 \pm 40 a$ & $231 \pm 35 b$ & $249 \pm 25 c$ \\
\hline
\end{tabular}

${ }^{\mathrm{z}}$ Roots of two-day-old seedlings were dip-inoculated with $5 \times 10^{5}$ chlamydospores per milliliter of $P$. indica or water before sowing. One-week-old seedlings were transferred to pots containing or not containing inoculum of $F$. culmorum and cultivated for an additional two weeks before assay. Control seedlings were mock-inoculated twice at two days and one week. Data are means of four independent replicates \pm standard deviation. The experiment was repeated twice with similar results. Different lowercase letters indicate significant differences at $P \leq 0.05$ by Tukey post hoc test. EU $=$ enzyme unit; FW $=$ fresh weight. 
culmorum DNA to plant DNA in root samples reflects both fungal abundance and the presence of intact plant cells. $F$. culmorum causes extensive cell death in barley roots, which ultimately results in root rot symptoms. Therefore, the qPCR method might overestimate the abundance of Fusarium DNA in necrotized root tissues that contain less-intact plant DNA. Using the qPCR method in greenhouse studies, Strausbaugh and associates (2005) found significant correlations between percent infected root area and Fusarium DNA quantities in $F$. culmorum-inoculated wheat and barley roots. However, in plants from field studies, they found no correlation between root-rot severities and amounts of Fusarium DNA. Another recent field study showed that development of Fusarium crown rot symptoms in wheat often, but not always, correlates with actual Fusarium colonization (Hogg et al. 2007). These studies show that qPCR results must be verified by independent methods to detect the fungus in roots. Accordingly, our microscopic analysis confirmed reduced levels of Fusarium infection in $P$. indica-preinoculated roots, thereby corroborating our interpretation of qPCR results (not shown).

Consistent with our results, several studies have demonstrated that $P$. indica and other mutualistic fungal endophytes may enable plants to more efficiently scavenge ROS or prevent ROS production under stress conditions (Baltruschat et al. 2008; Rodriguez et al. 2008 Sherameti et al. 2008; Sun et al. 2010; Waller et al. 2005). Our data suggest that antioxidant defense was maintained at a high level in $P$. indica-colonized roots in response to $F$. culmorum infection. It is well-established that necrotrophic pathogens such as Botrytis cinerea utilize production of ROS to accelerate cell death and facilitate subsequent infection (Govrin and Levine 2000). A recent study showed that inhibition of the oxidative burst in Arabidopsis resulted in resistance to $B$. cinerea infection (Yang et al. 2011). F. culmorum infection also triggers a sustained oxidative burst and cell death in the invaded plant tissues (Cuzick et al. 2009). Consistent with this, higher antioxidant capacity was associated with an increase in resistance of transgenic flax (Linum usitatissimum) seedlings to F. culmorum (Lorenc-Kukuła et al. 2007). Three key enzymes of flavonoid biosynthesis were upregulated in these flax plants resulting in an increased flavonoid content and high antioxidant capacity.

Based on our results and the aforementioned studies, we propose that the increase in resistance of barley roots to $F$. $\mathrm{cul}$ morum is, at least partly, mediated by $P$. indica-induced activation of antioxidant defense. Since higher antioxidant activity diminishes cell death induced by ROS, necrotization of plant tissue is consequently reduced, which is unfavorable to the necrotrophic pathogen. Yet, further studies are required to firmly establish the mechanism of endophyte-mediated resistance against pathogens in plant roots.

\section{MATERIALS AND METHODS}

\section{Plant material and fungal inoculation.}

Seeds of barley (Hordeum vulgare L. cv. Uschi) were surfacesterilized for $10 \mathrm{~min}$ in $0.25 \%$ sodium hypochlorite, were rinsed thoroughly with water, and were germinated for 2 days at $22^{\circ} \mathrm{C}$ on sheets of Whatman No. 1 filter paper in petri dishes. Germinated seeds were planted into $200-\mathrm{ml}$ pots (three plants per pot) filled with a 2:1 mixture of expanded clay (Seramis, Masterfoods, Verden, Germany) and Oil-Dri (equivalent to Terra Green, Damolin, Mettmann, Germany), were incubated in a growth chamber at $22^{\circ} \mathrm{C}$ day and $18^{\circ} \mathrm{C}$ night cycle, $60 \%$ relative humidity, and a photoperiod of $16 \mathrm{~h}\left(240 \mu \mathrm{mol} \mathrm{m} \mathrm{m}^{-2} \mathrm{~s}^{-1}\right.$ photon flux density), and were fertilized weekly with $0.1 \%$ Wuxal top N solution (N/P/K: 12/4/6; Schering, Düsseldorf, Germany).
Agar discs of $0.5 \mathrm{~cm}$ diameter covered by mycelium of $P$. indica (DSM 11827; Sharma et al. 2008) were placed in the center of $9-\mathrm{cm}$ petri dishes containing Aspergillus minimal medium solidified with $1.5 \%$ (wt/vol) agar and were incubated for 6 weeks at $26^{\circ} \mathrm{C}$ (Peškan-Berghöfer et al. 2004). Then chlamydospores were collected by flooding the surface of the plate with $10 \mathrm{ml}$ of sterile water containing $0.02 \%$ ( $\mathrm{vol} / \mathrm{vol})$ Tween 20 , followed by gentle scraping with a spatula. Spore suspension was filtered through two layers of Miracloth (Calbiochem, San Diego, CA, U.S.A.) to remove chunks of mycelium, was centrifuged $(3,000 \times g, 7 \mathrm{~min})$, and was resuspended in $0.02 \%$ Tween 20 , and the spore concentration was determined using a haemocytometer. For inoculation with $P$. indica, roots of two-day-old seedlings were immersed in $P$. indica spore suspension $\left(5 \times 10^{5} \mathrm{ml}^{-1}\right)$ before sowing (Verma et al. 1998). Control plants were treated with water containing $0.02 \%$ Tween 20 . Root colonization was determined in twoweek-old plants by magnified intersections method (McGonigle et al. 1990), after staining root fragments with $0.01 \%$ (wt/vol) acid fuchsin in lactoglycerol (Kormanik and McGraw 1982). Nine seedlings (three in each of three pots) were selected at random from each treatment and the whole root system was examined for fungal structures under a Zeiss Axioplan 2 microscope. The rest of the plants were used in further analyses only if all plants chosen for microscopic examination were well-colonized by $P$. indica (colonization was at least $50 \%$ among $1-\mathrm{cm}$-long root segments).

Fusarium culmorum KF 350 was grown on potato dextrose agar plates at $22^{\circ} \mathrm{C}$ (Jansen et al. 2005). For root inoculation, barley kernels were autoclaved twice for 25 min with a 24-h interval and were then inoculated with conidia of $F$. culmorum and incubated for one week at room temperature before being used as inoculum as described by Waller and associates (2005). One-week-old seedlings were removed from the pots and roots were washed thoroughly with sterile water. Then, seedlings were transplanted to $200-\mathrm{ml}$ pots filled with a $2: 1$ mixture of expanded clay and Oil-Dri containing or not containing the inoculum (eight to ten infected kernels per pot). Transplanted plants were cultured for an additional two weeks under the same conditions as described above.

\section{Quantification of $F$. culmorum in infected plants.}

The ratio of $F$. culmorum DNA to plant DNA was used to monitor the success of $F$. culmorum infection in barley. Roots of three-week-old barley plants were harvested from pot cultures and were washed intensively with sterile water before DNA extraction. DNA was isolated from the whole root system using DNAzol reagent (Invitrogen, Carlsbad, CA, U.S.A.) following the manufacturer's instructions. Furthermore, pure genomic DNA was isolated from roots of uninoculated plants and from aerial mycelia of F. culmorum scraped off the agar to construct calibration curves for a normalized measurement of infection. Extracted DNA was quantified using a NanoDrop 1000 spectrophotometer (Thermo Fisher Scientific, Waltham, MA, U.S.A.). Primers designed to amplify fragments of either the fungal Tril2 gene (involved in the trichothecene pathway) from the genomic DNA of $F$. culmorum KF350 (forward, 5'GCC CAT ATT CGC GAC AAT GT-3' and reverse, $5^{\prime}$-GGC GAA CTG ATG AGT AAC AAA ACC-3') or the plant EF1 $\alpha$ gene from barley genomic DNA (forward, $5^{\prime}$-TCT CTG GGT TTG AGG GTG AC-3' and reverse, 5'-GGC CCT TGT ACC AGT CAA GGT-3') were used (Nicolaisen et al. 2009; Nielsen et al. 2012). Total DNA (100 ng) served as template in each qPCR reaction. Amplifications were performed in a $20-\mu \mathrm{l}$ volume using $2 \times$ SYBR FAST master mix (KAPA Biosystems, Woburn, MA, U.S.A.) in a CFX96 real-time system (Bio-Rad Laboratories, Hercules, CA, U.S.A.), according to the follow- 
ing program: $3 \mathrm{~min}$ at $95^{\circ} \mathrm{C}, 40$ cycles of $15 \mathrm{~s}$ at $95^{\circ} \mathrm{C}, 10 \mathrm{~s}$ at $60^{\circ} \mathrm{C}, 10 \mathrm{~s}$ at $72{ }^{\circ} \mathrm{C}$. A melting curve was determined at the end of cycling to verify specificity of amplification. Cycle threshold $(\mathrm{Ct})$ values were calculated automatically by the BioRad CFX Manager software (version 2.1). Individual standard curves were developed by plotting the logarithm of known concentrations of F. culmorum DNA and barley DNA (twofold dilution series) against the $\mathrm{Ct}$ values. The amount of target DNA for unknown samples was extrapolated from the respective standard curves.

\section{Antioxidant assays.}

Roots of three-week-old barley plants were harvested from pot cultures and were washed intensively with sterile water before extraction. The entire excised root system was used for the antioxidant assays. Levels of reduced and oxidized forms of ascorbate and GSH and activities of antioxidant enzymes SOD, CAT, APX, DHAR, MDHAR, and GR were detected spectrophotometrically in root extracts as described (Baltruschat et al. 2008; Harrach et al. 2008).

\section{Peroxide analysis.}

Lipid hydroperoxides were extracted and assayed using the FOX assay as described (Do et al. 1996). Roots (0.2 g) were homogenized at 0 to $4^{\circ} \mathrm{C}$ in $2 \mathrm{ml}$ of methanol containing $0.01 \%$ butylated hydroxytoluene (BHT). Following centrifugation $\left(12,000 \times g, 10 \mathrm{~min}, 4^{\circ} \mathrm{C}\right)$, the supernatants $(0.1 \mathrm{ml})$ were mixed with $0.7 \mathrm{ml}$ of methanol containing $0.01 \%$ BHT. Then, $0.1 \mathrm{ml}$ water containing $2.5 \mathrm{mM} \mathrm{FeSO}, 2.5 \mathrm{mM}\left(\mathrm{NH}_{4}\right)_{2} \mathrm{SO}_{4}$, and $0.25 \mathrm{M} \mathrm{H}_{2} \mathrm{SO}_{4}$, as well as $0.1 \mathrm{ml}$ of methanol containing $40 \mathrm{mM}$ BHT and $1.25 \mathrm{mM}$ xylenol orange were added. Samples were incubated at room temperature for $30 \mathrm{~min}$ and absorbance at $560 \mathrm{~nm}$ was measured. The peroxide content was calculated based on a standard curve created by known concentrations of hydrogen peroxide as described (DeLong et al. 2002). The reactivity of 18:2-derived $\mathrm{LOOH}$ with the FOX reagent is nearly identical to $\mathrm{H}_{2} \mathrm{O}_{2}$ (DeLong et al. 2002).

\section{Statistical analysis.}

At least three independent experiments were carried out in each case. Four replicate pots of plants from each treatment were sampled for measurements. Statistical significance was analyzed with Student's $t$-test and analysis of variance followed by the Tukey post hoc test (Statistica 6.1, Statsoft, Tulsa, OK, U.S.A.). Differences were considered to be significant at $P<$ 0.05 .

\section{ACKNOWLEDGMENTS}

This research was supported by the Hungarian National Research Fund OTKA K83615 K61594 and IN 76570. The work was partly supported by resources from the RU 666 of the German Research Council to K.-H. Kogel. K.-H. Kogel, H. Baltruschat, and B. Barna designed research; B. D. Harrach, H. Baltruschat, and J. Fodor performed research; J. Fodor analyzed data; and B. Barna, J. Fodor, and K.-H. Kogel wrote the paper.

\section{LITERATURE CITED}

Apel, K., and Hirt, H. 2004. Reactive oxygen species: Metabolism, oxidative stress, and signal transduction. Ann. Rev. Plant Biol. 55:373-399.

Baltruschat, H., Fodor, J., Harrach, B. D., Niemczyk, E., Barna, B., Gullner, G., Janeczko, A., Kogel, K.-H., Schäfer, P., Schwarczinger, I., Zuccaro, A., and Skoczowski, A. 2008. Salt tolerance of barley induced by the root endophyte Piriformospora indica is associated with a strong increase in antioxidants. New Phytol. 180:501-510.

Boddu, J., Cho, S., Kruger, W. M., and Muehlbauer, G. J. 2006. Transcriptome analysis of the barley-Fusarium graminearum interaction. Mol. Plant-Microbe Interact. 19:407-417.

Conklin, P. L., Williams, E. H., and Last, R. L. 1996. Environmental stress sensitivity of an ascorbic acid-deficient Arabidopsis mutant. Proc. Natl. Acad. Sci. U.S.A. 93:9970-9974.

Cruz, C., Martins-Loução, M. A., and Varma, A. 2010. The influence of plant co-culture of tomato plants with Piriformospora indica on biomass accumulation and stress tolerance. Acta Hortic. 868:123-128.

Cuzick, A., Maguire, K., and Hammond-Kosack, K. E. 2009. Lack of the plant signalling component SGT1b enhances disease resistance to Fusarium culmorum in Arabidopsis buds and flowers. New Phytol. 181:901-912.

DeLong, J. M., Prange, R. K., Hodges, D. M., Forney, C.F., Bishop, M.C., and Quilliam, M. 2002. Using a modified ferrous oxidation xylenol orange (FOX) assay for detection of lipid hydroperoxides in plant tissue. J. Agric. Food Chem. 50:248-254.

Deshmukh, S. D., and Kogel, K.-H. 2007. Piriformospora indica protects barley from root rot caused by Fusarium graminearum. J. Plant Dis. Prot. 114:263-268.

Desmond, O. J., Manners, J. M., Schenk, P. M., Maclean, D. J., and Kazan, K. 2008. Gene expression analysis of the wheat response to infection by Fusarium pseudograminearum. Physiol. Mol. Plant Pathol. 73:40-47.

Do, T. Q., Schultz, J. R., and Clarke, C. F. 1996. Enhanced sensitivity of ubiquinone-deficient mutants of Saccharomyces cerevisiae to products of autoxidized polyunsaturated fatty acids. Proc. Natl. Acad. Sci. U.S.A. 93:7534-7539.

Dolatabadi, H. K., Goltapeh, E. M., Mohammadi, N., Rabiey, M., Rohani, N., and Varma, A. 2012. Biocontrol potential of root endophytic fungi and Trichoderma species against Fusarium wilt of lentil under in vitro and greenhouse conditions. J. Agric. Sci. Technol. 14:407-420.

Eltayeb, A. E., Kawano, N., Badawi, G. H., Kaminaka, H., Sanekata, T., Shibahara, T., Inanaga, S., and Tanaka, K. 2007. Overexpression of monodehydroascorbate reductase in transgenic tobacco confers enhanced tolerance to ozone, salt and polyethylene glycol stresses. Planta 225:1255-1264.

Fakhro, A., Andrade-Linares, D. R., von Bargen, S., Bandte, M., Buttner, C., Grosch, R., Schwarz, D., and Franken, P. 2010. Impact of Piriformospora indica on tomato growth and on interaction with fungal and viral pathogens. Mycorrhiza 20:191-200.

Foyer, C. H., and Noctor, G. 2005. Oxidant and antioxidant signalling in plants: A re-evaluation of the concept of oxidative stress in a physiological context. Plant Cell Environ. 28:1056-1071.

Franken, P. 2012. The plant strengthening root endophyte Piriformospora indica: Potential application and the biology behind. Appl. Microbiol. Biotechnol. 96:1455-1464.

Govrin, E. M., and Levine, A. 2000. The hypersensitive response facilitates plant infection by the necrotrophic pathogen Botrytis cinerea. Curr. Biol. 10:751-757.

Halliwell, B., and Chirico, S. 1993. Lipid peroxidation: Its mechanism, measurement, and significance. Am. J. Clin. Nutr. 57(suppl.):715-725.

Hamilton, C. E., and Bauerle, T. L. 2012. A new currency for mutualism? Fungal endophytes alter antioxidant activity in hosts responding to drought. Fungal Div. 54:39-49.

Harrach, B. D., Fodor, J., Pogány, M., Preuss, J., and Barna, B. 2008. Antioxidant, ethylene and membrane leakage responses to powdery mildew infection of near-isogenic barley lines with various types of resistance. Eur. J. Plant Pathol. 121:21-33.

Hogg, A. C., Johnston, R. H., and Dyer, A. T. 2007. Applying real-time quantitative PCR to Fusarium crown rot of wheat. Plant Dis. 91:10211028.

Jansen, C., Wettstein, D., Schäfer, W., Kogel, K.-H., Felk, A., and Maier, F. J. 2005. Infection patterns in barley and wheat spikes inoculated with wild-type and trichodiene synthase gene disrupted Fusarium graminearum. Proc. Natl. Acad. Sci. U.S.A. 102:16892-16897.

Khoshgoftarmanesh, A. H., Kabiri, S., Shariatmadari, H., Sharifnabi, B., and Schulin, R. 2010. Zinc nutrition effect on the tolerance of wheat genotypes to Fusarium root-rot disease in a solution culture experiment. Soil Sci. Plant Nutr. 56:234-243.

Kormanik, P. P., and McGraw, A. C. 1982. Quantification of vesiculararbuscular mycorrhizae in plant roots. Pages 37-45 in: Methods and Principles of Mycorrhizal Research. N. C. Schenck, ed. American Phytopathological Society, St. Paul, MN, U.S.A.

Kumar, M., Yadav, V., Tuteja, N., and Johri, A. K. 2009. Antioxidant enzyme activities in maize plants colonized with Piriformospora indica. Microbiology 155:780-790.

Li, Y. H., Yanagi, A., Miyawaki, Y., Okada, T., and Matsubara, Y. 2010. Disease tolerance and changes in antioxidative abilities in mycorrhizal strawberry plants. J. Jpn. Soc. Hortic. Sci. 79:174-178.

Lorenc-Kukuła, K., Wrobel-Kwiatkowska, M., Starzycki, M., and Szopa, J. 2007. Engineering flax with increased flavonoid content and thus Fusarium resistance. Physiol. Mol. Plant Pathol. 70:38-48.

McGonigle, T. P., Miller, M. H., Evans, D. G., Fairchild, G. L., and Swan, J. A. 1990. A new method which gives an objective measure of coloni- 
zation of roots by vesicular-arbuscular mycorrhizal fungi. New Phytol. 115:495-501.

Nicolaisen, M., Suproniene, S., Nielsen, L. K., Lazzaro, I., Spliid, N. H., and Justesen, A. F. 2009. Real time PCR for quantification of eleven individual Fusarium species in cereals. J. Microbiol. Methods 76:234240.

Nielsen, L. K. Jensen, J. D., Rodríguez, A., Jørgensen, L. N., and Justesen, A. F. 2012. TRI12 based quantitative real-time PCR assays reveal the distribution of trichothecene genotypes of $F$. graminearum and $F$. culmorum isolates in Danish small grain cereals. Int. J. Food Microbiol. 157:384-392

Peškan-Berghöfer, T., Shahollari, B., Giong, P. H., Hehl, S., Markert, C., Blanke, V., Kost, G., Varma, A., and Oelmüller, R. 2004. Association of Piriformospora indica with Arabidopsis thaliana roots represents a novel system to study beneficial plant-microbe interactions and involves early plant protein modifications in the endoplasmic reticulum and at the plasma membrane. Physiol. Plant. 122:465-477.

Qiang, X., Weiss, M., Kogel, K.-H., and Schäfer, P. 2012. Piriformospora indica-A mutualistic basidiomycete with an exceptionally large plant host range. Mol. Plant Pathol. 13:508-518.

Richter, J., Baltruschat, H., Kabrodt, K., and Schellenberg, I. 2011. Impact of arbuscular mycorrhiza on the St. John's wort (Hypericum perforatum) wilt disease induced by Colletotrichum cf. gloeosporioides. J. Plant Dis. Prot. 118:109-118.

Rodriguez, R. J., Henson, J., Van Volkenburgh, E., Hoy, M., Wright, L., Beckwith, F., Kim, Y., and Redman, R. S. 2008. Stress tolerance in plants via habitat-adapted symbiosis. ISME J. 2:404-416.

Serfling, A., Wirsel, S. G. R., Lind, V., and Deising, H. B. 2007. Performance of the biocontrol fungus Piriformospora indica on wheat under greenhouse and field conditions. Phytopathology 97:523-531.

Sharma, M., Schmid, M., Rothballer, M., Hause, G., Zuccaro, A., Imani, J., Kampfer, P., Domann, E., Schäfer, P., Hartmann, A., and Kogel, K.H. 2008. Detection and identification of bacteria intimately associated with fungi of the order Sebacinales. Cell. Microbiol. 10:2235-2246.

Sherameti, I., Tripathi, S., Varma, A., and Oelmüller, R. 2008. The rootcolonizing endophyte Piriformospora indica confers drought tolerance in Arabidopsis by stimulating the expression of drought stress-related genes in leaves. Mol. Plant-Microbe Interact. 21:799-807.
Strausbaugh, C. A., Overturf, K., and Koehn, A. C. 2005. Pathogenicity and real-time PCR detection of Fusarium spp. in wheat and barley roots. Can. J. Plant Pathol. 27:430-438.

Sun, C. A., Johnson, J., Cai, D. G., Sherameti, I., Oelmüller, R., and Lou, B. G. 2010. Piriformospora indica confers drought tolerance in Chinese cabbage leaves by stimulating antioxidant enzymes, the expression of drought-related genes and the plastid-localized CAS protein. J. Plant Physiol. 167:1009-1017.

Vadassery, J., Tripathi, S., Prasad, R., Varma, A., and Oelmüller, R. 2009. Monodehydroascorbate reductase 2 and dehydroascorbate reductase 5 are crucial for a mutualistic interaction between Piriformospora indica and Arabidopsis. J. Plant Physiol. 166:1263-1274.

Varma, A., Verma, S., Sudha, Sahay, N., Bütehorn, B., and Franken, P., 1999. Piriformospora indica, a cultivable plant-growth-promoting root endophyte. Appl. Environ. Microbiol. 65:2741-2744.

Verma, S., Varma, A., Rexer, K. H., Hassel, A., Kost, G., Sarabhoy, A., Bisen, P., Bütehorn, B., and Franken, P. 1998. Piriformospora indica, gen. et sp. nov., a new root-colonizing fungus. Mycologia 90:896-903.

Waller, F., Achatz, B., Baltruschat, H., Fodor, J., Becker, K., Fischer, M., Heier, T., Hückelhoven, R., Neumann, C., Wettstein, D., Franken, P., and Kogel, K.-H. 2005. The endophytic fungus Piriformospora indica reprograms barley to salt-stress tolerance, disease resistance, and higher yield. Proc. Natl. Acad. Sci. U.S.A. 102:13386-13391.

Weiss, M., Sykorova, Z., Garnica, S., Riess, K., Martos, F., Krause, C., Oberwinkler, F., Bauer, R., and Redecker, D. 2011. Sebacinales everywhere: Previously overlooked ubiquitous fungal endophytes. PloS One 6:e16793. Published online.

Yang, H., Zhao, X., Wu, J., Hu, M., and Xia, S. 2011. The benefits of exogenous NO: Enhancing Arabidopsis to resist Botrytis cinerea. Am. J. Plant Sci. 2:511-519.

Zarea, M. J., Hajinia, S., Karimi, N., Goltapeh, E. M., Rejali, F., and Varma, A. 2012. Effect of Piriformospora indica and Azospirillum strains from saline or non-saline soil on mitigation of the effects of $\mathrm{NaCl}$. Soil Biol. Biochem. 45:139-146.

Zhang, C. J., Liu, J. X., Zhang, Y. Y., Cai, X. F., Gong, P. J., Zhang, J. H., Wang, T. T., Li, H. X., and Ye, Z. B. 2011. Overexpression of SlGMEs leads to ascorbate accumulation with enhanced oxidative stress, cold, and salt tolerance in tomato. Plant Cell Rep. 30:389-398. 